\title{
A Gestural Interpretation of Variation and Variability in Minor Syllables
}

\author{
Becky Butler, Cornell University
}

\section{Background}

This paper presents an acoustic study of two languages, arguing that a single gestural account of minor syllables is not possible; thus, forms described as "minor syllables" do not constitute a coherent phonological class. Many mainland Southeast Asian languages are claimed to have not only monosyllabic and disyllabic words, but also sesquisyllables (Bennett 1995, Matisoff 1973, Svantesson and Karlsson 2004). Sesquisyllabic words comprise two types of syllables: (i) a heavy major syllable, which is right-aligned and is the locus of phonological contrast, and (ii) a weak minor syllable, usually containing a [Cə] sequence. However, there exist both systematic variation across languages in the types of segments appearing in minor syllables (1), and also unaccounted-for variability within individual languages regarding the phonetic realization of minor syllables (2).
a) [ro.bin]
b) [ti.jõk $]$
c) [tər.pah]
d) $\quad[\mathrm{m} .1 \partial \mathrm{m}]$

$\begin{array}{ll}\text { 'gourd' } & \text { Bunong } \\ \text { 'to point' } & \text { Jahai } \\ \text { 'to slap each other' } & \text { Pacoh } \\ \text { 'one' } & \text { Stieng }\end{array}$

(Butler 2012)

(Burenhult 2001)

(Watson 1964)

(Haupers 1969)
a) $\quad[$ mteh $] \sim[$ mo'teh $] \quad$ 'pepper'
Khmer

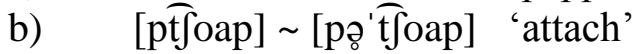
Khmer

Recent work has shown that an articulatory framework can account for some types of variability, particularly that of schwa-like transitions intervening in word-initial consonant sequences (cf. Kühnert et al. 2006 for French, Goldstein et al. 2007 for Georgian, Hermes et al. 2008 for Italian, Ridouane and Fougeron 2011 for Tashlhiyt Berber, inter alia). The data presented here are interpreted in light of Articulatory Phonology, which supposes that speech is composed of coordinated dynamical gestures, defined as bundles of articulatory movements toward targets in the vocal tract (Browman and Goldstein 1986, 1989, 1992; Saltzman and Kelso 1987). In addition, these gestures have the potential to overlap (Figure 1, left) or underlap (Figure 1, right).
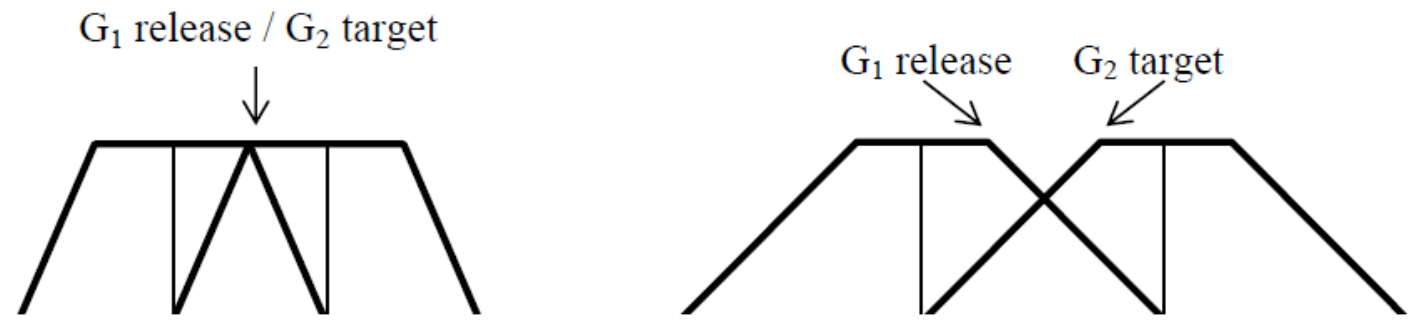

Figure 1: Overlapping and underlapping gestures

The present study compares minor syllables in two so-called sesquisyllabic languages Bunong and Khmer - and interprets the findings in light of Articulatory Phonology with the goal of answering the question: How can a gestural interpretation of minor syllables account for their inter-language variation and intra-language variability? 


\section{Khmer}

Khmer, a Mon-Khmer language and the national language of Cambodia, has a wealth of word-initial consonant clusters, some of which are reported to have intervening schwas and to therefore constitute minor syllables (Table 1). The Khmer data include vowels in 13 monosyllabic $\mathrm{C} \Lambda \mathrm{C}$ forms, 6 disyllabic $\mathrm{C} \Lambda \mathrm{C}$. ' $\mathrm{CVC}$ forms, and 20 purportedly sesquisyllabic $\mathrm{C}($ ə/g)CVC forms (using the clusters in double-outlined boxes in Table 1), produced by 18 native speakers. Each was recorded in a frame sentence.

\begin{tabular}{|c|c|c|c|c|c|c|c|c|c|c|c|c|c|c|c|}
\hline $\mathrm{Cl}$ & $\mathrm{S}$ & $\mathrm{h}$ & $r$ & 1 & $\mathrm{p}$ & $\mathrm{t}$ & $\mathrm{t} \int$ & $\mathrm{k}$ & $\mathrm{m}$ & $\mathrm{n}$ & $\mathrm{n}$ & $\eta$ & $?$ & $b$ & $\mathrm{~d}$ \\
\hline $\mathrm{p}$ & ps & ph & $\mathrm{pr}$ & $\mathrm{pl}$ & & $\mathrm{pt}$ & $\overline{p t \int}$ & pk & & pn & pn & py & p? & & $\mathrm{pd}$ \\
\hline $\mathrm{t}$ & & th & $\operatorname{tr}$ & $\mathrm{tl}$ & $\mathrm{tp}$ & & & tk & $\mathrm{tm}$ & tn & & ty & t? & $\mathrm{tb}$ & \\
\hline $\mathrm{t} \int$ & & $\mathrm{t} / \mathrm{h}$ & $\mathrm{t} \int \mathrm{r}$ & $\mathrm{t} \int 1$ & $t \int p$ & & & $\mathrm{t} f \mathrm{k}$ & $\mathrm{t} \int \mathrm{m}$ & $t \int n$ & & $\mathrm{t} \int \mathrm{y}$ & t $\int ?$ & $\mathrm{t} \int \mathrm{b}$ & $\mathrm{t} \int \mathrm{d}$ \\
\hline $\mathrm{k}$ & ks & $\mathrm{kh}$ & $\mathrm{kr}$ & $\mathrm{kl}$ & $\mathrm{kp}$ & $\mathrm{kt}$ & $\mathrm{kt} \int$ & & $\mathrm{km}$ & $\mathrm{kn}$ & $\mathrm{kn}$ & $\mathrm{kg}$ & & & \\
\hline $\mathrm{s}$ & & & $\mathrm{sr}$ & sl & $\mathrm{sp}$ & st & & sk & $\mathrm{sm}$ & sn & sn & sy & s? & $\mathrm{sb}$ & $\mathrm{sd}$ \\
\hline $\mathrm{m}$ & $\mathrm{ms}$ & $\mathrm{mh}$ & $\mathrm{mr}$ & $\mathrm{ml}$ & & $\overline{\mathrm{mt}}$ & $\mathrm{mt} \int$ & & & mn & $\mathrm{mn}$ & & m? & & \\
\hline 1 & & lh & & & $1 \mathrm{p}$ & & & lik & $\mathrm{lm}$ & & & $\ln$ & $1 ?$ & $\mathrm{lb}$ & \\
\hline
\end{tabular}

Table 1: Khmer consonant clusters (Based on Huffman 1972)

Despite the variability in the realization of sesquisyllabic words (2), the voicing of minor syllable [ə]/[ə] is predictably dependent on the voicing of $\mathrm{C} 1$. In particular, when $\mathrm{C} 1$ is voiced, underlap is present in $93 \%$ of tokens, and it is always voiced. When $\mathrm{C} 1$ is voiceless, underlap is present in $95 \%$ of tokens and is voiceless in $99 \%$ of repetitions. In addition, after accounting for $\mathrm{C} 1$ and $\mathrm{C} 2$ types, a linear regression shows that the durations of voiced and voiceless underlap are not significantly different from one another $(p=0.757)$ but both are significantly shorter than the underlying unstressed schwa found in disyllables $(p<0.0001)$. Finally, linear regression modeling reveals that underlap [ə] F1 is significantly lower than underlying [ $\Lambda$ ] F1, and that [ə] is more susceptible to influence from neighboring consonants (Figure 2).
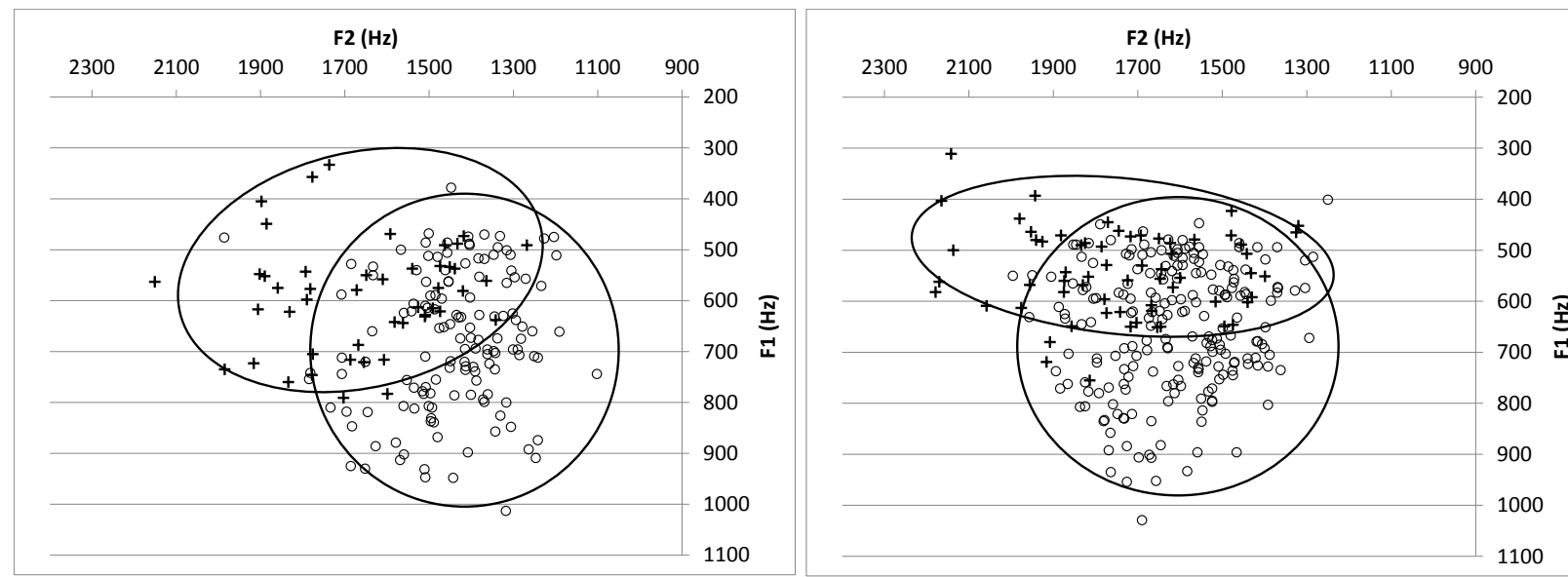

Figure 2: F1 and F2 values for underlap (+) and lexical (o) schwa with labial and alveolar C1s, respectively

These results suggest that the "minor syllable" vowel in Khmer is the result of gestural underlap, and therefore does not have an associated gesture or an articulatory target. 


\section{Bunong}

Bunong (or Phnong, Mnong) is also a Mon-Khmer language spoken in Cambodia and is also reported to have sesquisyllables. As presented by Bequette (2008) and Phaen et al. (2012), Bunong minor syllables $\left(\mathrm{C}_{1}\right.$ ə. $\left.\mathrm{C}_{2} \mathrm{VC}\right)$ can be distinguished from monosyllables with complex onsets $\left(\mathrm{C}_{1} \mathrm{C}_{2} \mathrm{VC}\right)$ by systematic differences in their consonant distributions (Table 2$)$. In particular, $\mathrm{C} 1$ in complex onsets may be any consonant in the inventory of the language, but in minor syllables with vowel nuclei, i.e. excluding those formed by a syllabic nasal, $\mathrm{C} 1$ must be one of $/ \mathrm{p} \mathrm{p}^{\mathrm{h}} \mathrm{c}^{\mathrm{h}} \mathrm{k} \mathrm{r} 1 /$. In addition, $\mathrm{C} 2$ in complex onsets is limited to $/ \mathrm{r} 1 \mathrm{w} \mathrm{j} /$. Disyllabic words in Bunong are extremely rare. The Bunong data include $7 \mathrm{CCVC}$ forms, 12 purportedly sesquisyllabic $\mathrm{C} ə$. ' $\mathrm{CVC}$ forms and $21 \mathrm{C} \Lambda \mathrm{C}$ forms, produced by 12 speakers.

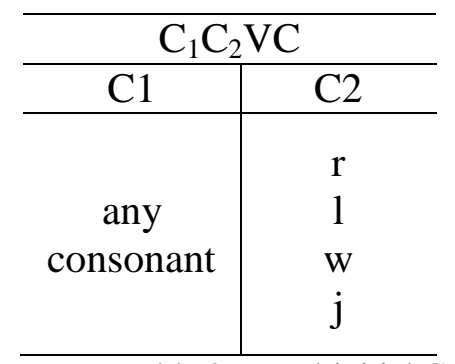

Table 2: Word-initial $\underline{\mathrm{C}}_{1} \underline{\mathrm{C}}_{2} \mathrm{VC}$ and $\underline{\mathrm{C}}_{1} \underline{\partial} \underline{\mathrm{C}}_{2} \mathrm{VC}$ sequences in Bunong

\begin{tabular}{|c|c|c|}
\hline \multicolumn{3}{|c|}{$\mathrm{C}_{1} \ni . \mathrm{C}_{2} \mathrm{VC}$} \\
\hline C1 & $\mathrm{V}$ & $\mathrm{C} 2$ \\
\hline $\mathrm{p} \quad \mathrm{p}^{\mathrm{h}}$ & & any \\
\hline$c^{h} \quad k$ & $\partial$ & except \\
\hline r 1 & & $\begin{array}{l}\text { liquids or } \\
\text { glides }\end{array}$ \\
\hline
\end{tabular}

Results show that predictable voiced and voiceless underlap is present in CCVC forms. In Cr clusters ([sr, mr, $\mathrm{pr}]$ ), underlap is present in $89 \%$ of tokens and is always voiced. Underlap is present in $98 \%$ of [kl] tokens and in $13 \%$ of [ $\mathrm{yl}]$ tokens and is always voiceless in both. In addition, minor syllable schwa $\left(\mathrm{C}_{\underline{\imath}}\right.$. ' $\left.\mathrm{CVC}\right)$ is significantly longer than $\underline{\mathrm{CCVC}}$ transitional schwa, i.e underlap, while significantly shorter than $\mathrm{C}_{\underline{\Lambda}} \mathrm{C}$ vowels $(p<0.0001)$. Finally, $\mathrm{F} 1$ is significantly lower for $\underline{\mathrm{CCVC}}$ underlap than for minor syllable $\mathrm{C} \underline{\underline{\partial}}$. ' $\mathrm{CVC}$ vowels $(p<0.0001)$, as seen in Figure 3, left. But $\mathrm{F} 1$ is not significantly different for $\mathrm{C} \underline{\underline{\jmath}} \cdot{ }^{\prime} \mathrm{CVC}$ and $\mathrm{C} \underline{\Lambda} \mathrm{C}$ vowels (Figure 3 , right). No significant differences in F2 were found, although unusually high or low F2 values for $\mathrm{C}_{\underline{\underline{a}}}$. 'CVC vowels are positively correlated with shorter vowel duration $\left(p=0.0013, \mathrm{R}^{2}=\right.$ 0.18 ) and likely result from insufficient time for full target attainment.

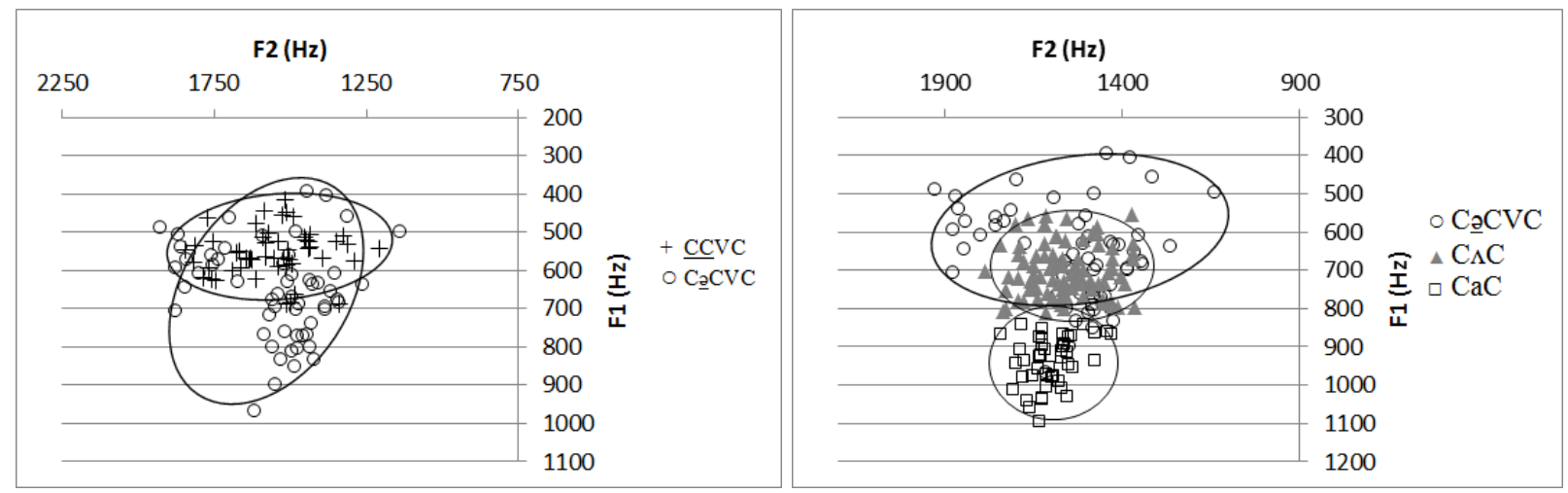

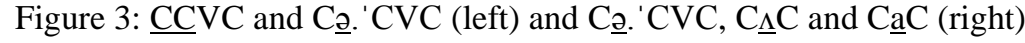

Thus, Bunong minor syllable schwa is distinct from underlap, indicating it has an associated gestural with gestural target, yet it is shorter than monosyllable $/ \Lambda$ / because it is unstressed. Thus Bunong sesquisyllables are in fact disyllables. 


\section{Conclusion}

Together, these results demonstrate that not only does the gestural realization of minor syllables differ across languages but in fact that minor syllable is not a coherent phonological entity. Variation in minor syllables across languages is due to the fact that some minor syllable nuclei have associated gestures, while others do not. As demonstrated, in Khmer the minor syllable vowel has no gestural target, whereas in Bunong it does. Additionally, intra-language variability is accounted for: In Khmer, the variable presence of the "minor syllable" vowel is due to variability in gestural alignment, whereas the minor syllable vowel of Bunong is always realized.

\section{References}

Bequette, R. (2008). Participant Reference, Deixis, and Anaphora in Bunong Narrative Discourse (MA). Graduate Institute of Applied Linguistics.

Browman, C., \& Goldstein, L. (1986). Towards an articulatory phonology. Phonology Yearbook, 3, 219-252.

Browman, C., \& Goldstein, L. (1989). Articulatory gestures as phonological units. Phonology, 6, 201-251.

Browman, C., \& Goldstein, L. (1992). Articulatory phonology: An overview. Haskins Laboratories Status Report on Speech Research.

Burenhult, N. (2001). Jahai phonology: A preliminary survey. Mon-Khmer Studies, 31, 29-45.

Butler, B. (2012). A gestural deconstruction of the minor syllable. Presented at the Mainland Southeast Asian Languages: The State of the Art in 2012, Leipzig.

Goldstein, L., Chitoran, I., \& Selkirk, E. (2007). Syllable structure as coupled oscillator modes: Evidence from Georgian vs. Tashlhiyt Berber. ICPhS, XVI, 241-244.

Haupers, R. (1969). Stieng phonemes. Mon-Khmer Studies, 3, 131-137.

Hermes, A., Grice, M., Mücke, D., \& Niemann, H. (2008). Articulatory indicators of syllable affiliation in word initial consonant clusters in Italian. 8th International Seminar on Speech Production, 433-436.

Kuhnert, B., Hoole, P., \& Moonshammer, C. (2006). Gestural overlap and C-center in selected French consonant clusters. Sciences de l'Homme et de la Societe.

Matisoff, J. (1973). Tonogenesis in Southeast Asia. (L. Hyman, Ed.) Consonant Types and Tone, Southern California Occasional Papers in Linguistics, 1.

Phaen, T., Sok, M., \& Bequette, T. (2012). Bunong-Khmer Bilingual Dictionary. Mondulkiri Province, Cambodia: International Cooperation Cambodia, READ Project.

Ridouane, R., \& Fougeron, C. (2011). Schwa elements in Tashlhiyt word-initial clusters. Laboratory Phonology, 2(2), 275-300.

Saltzman, E., \& Kelso, J. A. S. (1987). Skilled actions: A task dynamic approach. Psychological Review, 94, 84-106.

Svantesson, J. O., \& Karlsson, A. M. (2004). Minor syllable tones in Kammu. International Symposium on Tonal Aspects of Languages: With Emphasis on Tone Languages (pp. 177-180).

Watson, R. (1964). Pacoh phonemes. Mon-Khmer Studies, 1, 135-148. 